\title{
Fungal sepsis and Indications of antifungal prophylaxis and treatment in neonatal intensive care units : A review
}

\author{
M Hassan', B H N Yasmeen², N Begum ${ }^{3}$
}

\section{I ntroduction}

Fungal septicemia is a devastating disease in the neonate, especially in the preterm low birth weight (PTLBW) infant. They are vulnerable to disseminated fungal sepsis due to lack of innate and the acquired immunity. Invasive fungal infection, predominantly due to Candida species, is an increasingly common cause of mortality and morbidity in preterm and sick newborn infants ${ }^{1}$. In the last 25 years the incidence is increasing may be due to the increased survival rates of preterm low birth or very low birth weight (VLBW) and sick neonates. Specially due to the intensive nature of the care with many invasive procedures what these infants receive in the neonatal intensive care unit.

Candida species are commensal organisms that colonise the skin, gastrointestinal tract and the female genitourinary tract. $^{2}$

The vast majority of fungal infections in preterm neonates are due to Candida species, The early NICU course favors colonization and proliferation of fungi since many VLBW infants have central vascular catheters and are exposed to broad-spectrum antibiotics and parenteral nutrition. Mortality figures can vary between $15 \%$ and $59 \%$ and Candida species (Candida albicans, C. krusei and C. parapsilosis) are considered the third most common causeof late-onset sepsis in the $\mathrm{NICU}^{3,4}$ Incidence rates have rangedfrom $2.6 \%$ to $16.7 \%$ among the VLBW infants and from $5.5 \%$ to $20 \%$ among extremely low birth weight infants (ELBW), with a mortality rate of around $30 \%{ }^{2}$ In one study fungal septicemia was demonstrated as a devastating disease in the neonate, in the VLBW premature infant who is especially vulnerable to disseminated fungal sepsis. ${ }^{5}$

Invasive fungal infection is defined as positive fungal cultures from blood, cerebrospinal fluid or urine (collected by suprapubic aspiration or bladder catheterisation). Invasive fungal infection is usually nosocomially acquired. It accounts for approximately $10 \%$ of all first episodes of late onset sepsis in VLBW babies. ${ }^{6}$ The incidence peaks between 2-6 weeks of age and in the UK the median age at diagnosis is 14 days. $^{7}$

\section{Correspondence}

Dr. Mahmuda Hassan

Associate professor

Dept. of Pediatrics

Ad-din Medical college Hospital, Dhaka

E-mail mahmudahasn@yahoo.com

\section{Epidemiology}

Hospital-acquired pathogens, including various Candida species are increasing, especially in the neonatal intensive care unit (NICU), causing considerable morbidity and mortality in preterm infants. $^{3}$ In VLBW infant Candida albicans (C. albicans) is the third most common cause of neonatal late onset sepsis (LOS), which occurs after the first 7 of life. This was illustrated in a multicenter study of the National Institute of Child Health and Human Development (NICHD) Neonatal Research Network that evaluated 6956 VLBW infants (range of birth weight from 401 to $1500 \mathrm{~g}$ ) admitted over a two-year period from 1998 to $2000 .^{8}$ In another study C. Albicanswas the causative agent in $6 \%$ of first episodes of LOS following Coagulase negative staphylococcus $48 \%$ and Staphylococcus aureus 8\% in frequency. ${ }^{8}$

The incidence of Candida infections is greatest in ELBW infants as demonstrated by a study from the National Nosocomial Infections Surveillance (NNIS) system that included 130, 523 patients admitted to 128 NICU between 1995 and $2004 .^{8}$

\section{Pathogenesis and the host defenses}

The immature lymphocyte and antibody system predisposes VLBW infants to skin and mucosal fungal colonization, while deficient innate host defense mechanisms predispose them to dissemination and overwhelming infection. Neutrophils play a major role in antifungal defense, ingesting and killing Candida, requiring antibodies, cytokines, and activation of the C3 complement component, all of which are decreased in preterm infants compared with term infants and adults. ${ }^{9}$ Macrophages are also important in the control of fungal colonization and infection, since they ingest and kill Candida without a requirement for complement activation; however, their adherence, phagocytosis, and oxidative killing are impaired in preterm infants, affecting their ability to resist fungal infection ${ }^{10}$, cytokines contribute to innate immunity to fungal infection, through direct inhibition of fungal proliferation and through enhancement of cell-mediated fungicidal activity. ${ }^{11}$

Moreover in preterm<28 weeks of gestation, skin layer is very thin and 3 layered, the compromise of the barrier defense system, immaturelymphocyte, deficient neutrophil number and function with poor antibody production predispose them to invasive fungal infection. ${ }^{10}$ End organ damage is more common and severe in systemic fungalinfections and can involve the kidneys, brain, lungs, eyes, liver, spleen, bones and joints. ${ }^{12}$ 


\section{Risk factors}

Candida infection is strongly associated with neutropenia, recent surgery or the presence of intravenous lines, and previous colonisation by the organism is considered to be an independent risk factor. ${ }^{13}$

Additional risk factors that have been identified are: ${ }^{13}$

- Prior exposure to broad spectrum antibiotic specially $3^{\text {rd }}$ generation cephalosporin.

- VLBW and ELBW neonates.

- Gestational age of $<32$ weeks

- Apgar score at five minutes of $<5$

- Presence of a central venous line, UAC, UVC

- Endotracheal intubation

- Prior fungal colonisation

- Immature skin structure

- Prior use of steroids.

- Circulatory shock

- Parenteral nutrition $>5$ days

- Use of intravenous lipid emulsion for $>7$ days

- Exposure to an $\mathrm{H} 2$ receptor blocker

- Length of hospital stay $>7$ days.

Spread may also occur from patient to patient or through a colonized health care worker ${ }^{14,15}$ as seen in different studies.

\section{Classifications \\ Congenital Infection}

Congenital candidiasis is uncommon and occurs due to ascending infection through the birth canal due to introduction of intrauterine devices and cervical suture increase the risk.

\section{Acquired Systemic Infection}

Acquired late onset systemic fungal infections occur in babies with the risk factors ${ }^{16,17}$ as well as in presence of ventriculoperitonial shunt.

\section{Clinical features}

The classic clinical picture of systemic candidiasis in neonates is indistinguishable from bacterial sepsis. Common presenting symptoms are worsening respiratory function, apnea, thrombocytopenia and localized signs of candidal infection at one or more of the following sites:

- Skin and mucous membranes: there may be thrush, diaperrash or other areas.

- Central nervous system: Meningitis is present in up to $64 \%$ of fatal cases, and survivors have a high incidence of severe sequelae including hydrocephalus, psychomotor and mental retardation, and aqueductal stenosis

- Eyes: Fundoscopic examination is essential for early diagnosis of invasive disease, as the incidence of Candida endophthalmitis is as high as $50 \%$.

- Heart: Candida endocarditis is the 2nd most common form of endocarditis in VLBW infants. Clinical findings may include cardiac murmurs, petechiae, skin abscesses, arthritis, hepatomegaly and splenomegaly. Right-sided intracardiac fungal masses can manifest with heart failure or even with pulmonary fungal embolism.

- Kidneys: Candida is the most frequent cause of urinary tract infection in intensive care nurseries. Up to $50 \%$ of these babies have candidemia and are predisposed to renal candidiasis, with development of renal fungus balls or abscesses and unilateral or bilateral renal obstruction. Renal insufficiency may be the first clinical manifestation of invasive candidiasis.

- Bones and Joints: Warmth and swelling of the extremities in combination with radiographic evidence of osteolysis or arthritis.

\section{Diagnosis}

Confirming the diagnosis by laboratory tests is difficult and a high index of suspicion is required.

All indwelling catheter aspirates, blood, urine must be examined for hyphae or budding yeast. In contrast to the high sensitivity of blood cultures in detecting bacteremia, the sensitivity of blood cultures in diagnosing candidemia is as low as $50 \%$ to $80 \% .{ }^{18}$

- Thrombocytopenia is almost invariable feature but not diagnostic.

- Hyperthermia is a significant presenting feature of invasive fungal infection.

- Candida may grow slowly in culture contributing to the delay in the diagnosis.

- Once the diagnosis of invasive candida infection is suspected or confirmed, investigations for signs of dissemination must be undertaken by direct ophthalmologic examination, abdominal ultrasound, ECHO and neuroimaging.

\section{Antifungal Prophylaxis}

Risk factors for neonatal candidiasis have been evaluated and Antifungal Prophylaxis can be given in high risk group.

Prophylaxis of high-risk infants has been found to be effective, particularly in neonatal intensive care units with a high incidence of candidemia.

Miconazole, nystatin, fluconazole and amphotericine B with different trial are given below.

\section{Drugs reported to have been used in antifungal prophylaxis}

\begin{tabular}{|c|c|c|c|}
\hline Name & Route & Dose & Evidence for use \\
\hline Miconazole & Oral & $\begin{array}{l}1 \mathrm{ml} .2-4 \text { times } \\
\text { daily around } \\
\text { the mouth }\end{array}$ & $\begin{array}{l}\text { One RCT: no significant } \\
\text { effect on invasive fungal } \\
\text { infection. }\end{array}$ \\
\hline Nystatin & Topical or oral & $\begin{array}{l}100,000 \text { IU, } \\
1 \mathrm{~mL} 8 \text { hourly }\end{array}$ & $\begin{array}{l}\text { Two RCTs: significant } \\
\text { reduction in invasive } \\
\text { fungal infection. }(P<0.001)^{20}\end{array}$ \\
\hline Fluconazole & Oral or intravenous & $\begin{array}{l}<2 \text { weeks of age } \\
6-12 \mathrm{mg} / \mathrm{kg} \\
\text { every } 72 \text { hours } \\
>2 \text { weeks of age } \\
6-12 \mathrm{mg} / \mathrm{kg} \\
\text { every } 48 \text { hours }\end{array}$ & $\begin{array}{l}\text { Meta-analysis : significant } \\
\text { reduction in invasive } \\
\text { fungal infection. }\end{array}$ \\
\hline Amphotericin B & Intravenous & $\begin{array}{l}\text { I Amphotericin B: } \\
\text { flucytosine upon } \\
\text { brand used }^{21} \\
\text { Flucytosine: } \\
50 \mathrm{mg} / \mathrm{kg} \text { iv } \\
12 \text { hourly. }\end{array}$ & $\begin{array}{l}\text { No trials in } \\
\text { neonatal population }\end{array}$ \\
\hline
\end{tabular}

In addition to antifungal prophylaxis standard infection control measures such as hand washing,aseptic intravascular catheter handling, minimising duration of total parenteral nutrition and endotracheal intubation and rationalization of intravenous antibiotic use required.

\section{Antifungal Treatment}

Prompt and aggressive use of antifungal treatment is justified in a clinically septic neonate, especially the one with neutropenia with a 
raised serum concentration of $\mathrm{C}$ reactive protein, who does not show a satisfactory response to antibiotics.

Early empiric treatment with the following drugs is imperative to successful management of candidemia in immune-compromised neonates along with the risk factors as mentioned earlier.

\section{Antifungal Medications}

Amphotericin B : has been the mainstay of antifungal therapy for candidemia in the NICU but newer agents such as echinocandins and azoles are currently being evaluated. Liposomal Amphotericin B is safer than amphotericin B.

Oral Nystatin suspension $0.5 \mathrm{ml}$ OD is given to infants $<27$ weeks gestation and/or $<750 \mathrm{gms}$ from birth until removal of central venous catheters and whilst on broad spectrum antibiotics. This is shown to reduce both colonisation of the gastrointestinal tract and the rate of invasive candidiasis.

Fluconazole : A triazole that has far less toxicity, has been used with some success. It has the additional advantage of being available as an oral formulation. It is used in the dose of 5-6 $\mathrm{mg} / \mathrm{kg}$ per day orally or intravenously. In a study of 24 neonates with culture proven candidiasis, who were treated with fluconazole showed both clinical andmicrobiological cure was achieved in $96 \%$ babies. ${ }^{23}$ Fluconazole prophylaxis is effective in reducing the rate of colonization and progression to systemic infection in neonatal units with a high rate of fungal infection ( $>10 \%$ ).

In candidemia duration of treatment is 3 weeks or resolution of signs/ symptoms of the disease.

\section{Side effects of the antifungal medications}

\section{Fluconazole}

It is hepatotoxic. So, monitor liver function enzymes at least weekly.

\section{Amphotericin B}

\section{General reactions}

Hypotension, fever (usually occurs within 1-2 hours after the start of the infusion and subsides within 4 hours after discontinuation), shaking chills. Record vital signs (heart rate, blood pressure, temperature, respiratory rate) at baseline and observe first 5 minutes; record every 15 minutes for the first 30 minutes; and then every 30 minutes thereafter.

Renal effects : Hypokalemia, nephrotoxicity, hypomagnesemia. Monitor laboratory values (BUN, creatinine, and electrolytes) at least three times weekly during the first 2 weeks of therapy; then once or twice weekly thereafter. Adverse effects appear to be less common in neonates than in older children and adults.

On the other hand Liposomal Amphotericin B allows targeted antifungal therapy with less toxicity. The drug is cleared through the reticuloendothelial system allowing higher liver and spleen concentrations and reduced renal concentrations.

\section{Conclusion}

At present era great advancement of neonatal care for the extreme premature and incredible low birth weight babies in the neonatal care unit with prolong hospital stay with several invasive procedure, now a day fungal sepsis is an emerging issue worldwide. So, high index of suspicion with prompt initiation of treatment, proper use of anti fungal prophylaxis in case of high risk group is required for better outcome of the vulnerable neonates.

\section{References}

1. Stoll, B. J., N. Hansen, A. A. Fanaroff, L. L. Wright, W. A. Carlo, R. A. Ehrenkranz, J. A. Lemons, E. F. Donovan, A. R. Stark, J. E. Tyson, W. Oh, C. R. Bauer, S. B. Korones, S. Shankaran, A. R. Laptook, D. K. Stevenson, L. A. Papile, and W. K. Poole. To tap or not to tap: high likelihood of meningitis without sepsis among very low birth weight infants. Pediatrics. 2004; 113:1181-1186.

2. Bendel CM. Nosocomial neonatal candidiasis. Pediatr Infect Dis J 2005; 24(9): 831-832

3. Rodriguez $D$, Almirante $B$, Park $B$ J, et al. Candidemia in neonatal intensive care units: Barcelona, Spain. Pediatr Infect Dis J 2006; 25(3): 224-229

4. Chapman RL. Prevention and treatment of candida infections in neonates. Seminars in Perinatology 2007; 31(1): 39-46.

5. Driessen M, Ellis J, Cooper, $\mathrm{P}$, et al. Fluconazole vs. amphotericin B for the treatment of neonatal fungal septicemia: A prospective randomized trial. Pediatr Infect Dis J 1996;15(12): 1107-1112

6. Stoll B.J., Hansen N., Fanaroff A.A. et al. Late-onset sepsis in very low birth weight neonates: the experience of the NICHD Neonatal Research Network. Pediatrics 2002; 110: 285-91.

7. Clerihew L., Lamagni T.L., Brocklehurst P. et al. Invasive fungal infection in very low birth weightinfants: a national prospective surveillance study.Arch Dis Child Fetal Neonatal Ed 2006; 91: F188-192.

8. Fridkin SK, Kaufman D, Edwards JR, et al. Changing incidence of Candida bloodstream infections among NICU patients in the United States: 1995-2004. Pediatrics 2006; 117:1680.

9. Diamond, R. D., R. Krzesicki, and W. Jao. Damage to pseudohyphal forms of Candida albicans by neutrophils in the absence of serum in vitro. J. Clin. Investig. 1978.: 61:349359.

10. Marodi, L., and R. B. Johnston, Jr. 2004. Developmental immunology, p. 1487-1489. In R. A. Polin, W. W. Fox, and S. H. Abman (ed.), Fetal and neonatal physiology. The W.B. Saunders Co., Philadelphia, Pa.

11. Kilpatrick, L., and M. C. Harris. 2004. Cytokines and the inflammatory response in the fetus and neonate, p. 1555-1571. In R. A. Polin, W. W. Fox, and S. H. Abman (ed.), Fetal and neonatal physiology. The W. B. Saunders Co., Philadelphia, Pa.

12. Benjamin DK Jr, Kelly Ross, Ross E McKinney, Benjamin DK, Auten R, Fisher RG. When To Suspect Fungal Infection In Neonates: A Clinical Comparison Of Candida Albicans and Candida Parapsilosis Fungemia With Coagulse-Negative Staphylococcal Bacteremia. Paediatrics 2000; 106: 712-8.

13. Chapman RL. Candida infections in the neonate. Current Opinion in Pediatrics 2003; 15: 97-102.

14. Robertson NR. Neonatal infections. In. Robertson Textbook of Neonatology, 2nd edn. Churchill Living Stone: 1992, p. 984-5.

15. Baley JE, Kliegman RM, Fanaroff AA. Disseminated fungal infections in very low birth weight infants: clinical manifestations and epidemiology. Paediatrics 1992; 73:144-5

16. Huang YC, Li CC, Liu TY, Lien RI, Chou YH, Wu JL, et al. Association of fungal colonization and invasive disease in very low birth weight infants. Paediatr Infect Dis J r 1992; 17:819-22.

17. Baley JE, Kliegman RM, Boaerbaum B, Faranaoff AA. Fungal colonization in the very low birth weight infant. Paediatrics 1986; 78:225-32.

18. Pizzo PA, Robichaud KJ, Gill FA, Witebsky FG. Empiric antibiotic and antifungal therapy for cancer patients with prolonged fever and granulocytopenia. Am J Med. 1982; 72:101-110. 